\title{
PEMILIHAN MODEL TERBAIK PADA ANALISIS REGRESI LINIER MULTIVARIAT DENGAN KRITERIA AIC
}

\section{Best Model Election on Multivariate Linear Regression Analysis with AIC Criterion}

\author{
M. S. Noya Van Delsen ${ }^{1}$, S. N. Aulele ${ }^{2 *}$, H. W. M. Patty ${ }^{3}$ Natalia Kelbulan $^{4}$ \\ 1,2,3,4 Jurusan Matematika Fakultas MIPA Universitas Pattimura \\ Jln. Ir. M. Putuhena, Kampus Unpatti, Poka-Ambon, 97233, Provinsi Maluku, Indonesia \\ e-mail:1 1 marlonnvd@gmail.com ; 2*salmon.aulele@yahoo.com ; ${ }^{4}$ nataliakelbulan21@gmail.com \\ Corresponding author*
}

\begin{abstract}
Abstrak
Kesejahteraan merupakan tujan utama pembangunan sebuah negara. Salah satu aspek penting yang dapat digunakan untuk mengukur tingkat kesejahteraan adalah kualitas fisik penduduk itu sendiri, dua diantaranya adalah angka kematian bayi dan status gizi buruk. Model regresi multivariat adalah model regresi dengan lebih dari satu variabel respon yang saling berkorelasi dan satu atau lebih variabel prediktor. Tujuan dari penelitian ini adalah untuk mengetahui faktor-faktor apa saja yang mempengaruhi angka kematian bayi dan status gizi buruk di Provinsi Maluku dengan menggunakan regresi linier multivariat. Hasil penelitian menunjukan bahwa persentase angka kematian bayi tertinggi yaitu di Kabupaten Maluku Tenggara Barat dan persentase status gizi buruk tertinggi di Kabupaten Kepulauan Aru. Faktor-faktor yang signifikan mempengaruhi angka kematian bayi dan status gizi buruk di Provinsi Maluku dengan menggunakan regresi linier multivariat yaitu persentase ASI Ekslusif $\left(\mathrm{X}_{1}\right)$, persentase kunjungan ibu hamil ke Puskesmas untuk memeriksa kandungan $\left(\mathrm{X}_{3}\right)$, persentase jumlah sarana kesehatan $\left(X_{4}\right)$ dan persentase penduduk miskin $\left(X_{5}\right)$. Model terbaik untuk $Y_{1}$ dan $Y_{2}$ diperoleh dengan nilai AIC sebesar 8,440420 dan 0,6999986.
\end{abstract}

Kata Kunci : Model Regresi Linier Multivariat, Angka Kematian Bayi, Status Gizi Buruk, AIC

\begin{abstract}
Welfare is the main objective of developing a country. One important aspect that can be used to measure the level of welfare is the physical quality of the population itself, two of which are infant mortality and poor nutritional status. Infant mortality and poor nutritional status in an area can be influenced by more than one variable. The multivariate regression model is a regression model with more than one correlated response variable and one or more predictor variables. The purpose of this study was to find out what factors influence infant mortality and poor nutritional status in Maluku Province by using multivariate linear regression. The results showed that the highest percentage of infant mortality was in West Southeast Maluku Regency and the highest percentage of malnutrition status was in the Aru Islands Regency. Factors that significantly influence infant mortality and poor nutritional status in Maluku Province using multivariate linear regression, namely the percentage of exclusive breastfeeding (X1), the percentage of visits of pregnant women to the health center to check the content (X3), percentage of health facilities (X4) and percentage of poor people (X5). The best models for $Y_{1}$ and $Y_{2}$ are obtained with AIC values of 8,440420 and 0,6999986.
\end{abstract}

Keywords: Multivariate Regression Model, Infant Mortality, Poor Nutritional Status, AIC 


\section{PENDAHULUAN}

Menurut PBB dan WHO, kematian adalah hilangnya semua tanda-tanda kehidupan secara permanen yang bisa terjadi setiap saat setelah kelahiran hidup. Perubahan jumlah kematian (naik turunya) disetiap daerah tidaklah sama,tergantung pada berbagai macam keadaan[1]. Besar kecilnya tingkat kematian ini dapat merupakan petunjuk atau indikator bagi tingkat kesehatan dan tingkat kehidupan penduduk di suatu wilayah Angka Kematian Bayi (AKB) adalah jumlah penduduk yang meninggal sebelum mencapai usia satu tahun yang dinyatakan dalam 1000 kelahiran hidup pada tahun yang sama[8]. Angka kematian bayi juga merupakan indikator yang lazim digunakan untuk menetukan derajat kesehatan masyarakat, baik pada tingkat provinsi maupun nasional. Selain itu program-program kesehatan di Indonesia banyak yang menitikberatkan pada upaya penurunan Angka Kematian Bayi [4].

Berdasarkan data yang diperoleh, terlihat bahwa rata-rata jumlah kematian bayi di Provinsi Maluku Tahun 2015 adalah 35 dimana Kabupaten Maluku Tenggara Barat (MTB) dan Kabupaten Maluku Tengah (Malteng) memiliki jumlah kematian bayi tertinggi yaitu 66 bayi [2]. Jumlah tersebut dianggap terlampau tinggi, karena jika dibandingkan dengan target MDG`s maka angka kematian bayi pertahun hanya 17 bayi. Angka-angka kematian tersebut seharusnya dapat di perhatikan oleh pihak-pihak yang berkompeten, sehingga dapat menindak lanjuti guna meminimalisir dan menyelamatkan manusia (bayi), sebagai aset bangsa khususnya daerah Maluku [3]. Selain AKB, indikator lain yang digunakan untuk menentukan derajat kesehatan masyarakat adalah Status Gizi Buruk (SGB).

Dalam perhitungan kedua indikator ini, ternyata mempunyai kesamaan yaitu dipengaruhi oleh faktor-faktor yang sama [4]. Namun dalam penerapannya hal ini tidak dapat diberlakukan secara nasional. Ini dikarenakan letak geografis dan kondisi di setiap daerah yang ada di Indonesia memiliki perbedaan. Sehingga dalam penelitian ini akan dilakukan pemilihan model terbaik untuk faktor-faktor yang berpengaruh terhadap angka kematian bayi dan status gizi buruk di Provinsi Maluku pada regresi linier multivariat dengan menggunakan nilai AIC.

\section{METODE PENELITIAN}

\subsection{Data dan Variabel Penelitian}

Data yang digunakan adalah data sekunder yang diperoleh dari Badan Pusat Statistik (BPS) Provinsi Maluku, Profil Kesehatan Provinsi Maluku serta Survei Sosial Ekonomi Nasional (SUSENAS) tahun 2015. Sampel yang digunakan dalam penelitian ini sebanyak 11, yang merupakan kabupaten/kota yang ada di Provinsi Maluku. Dalam penelitian ini variabel yang digunakan yaitu variabel respon dan variabel prediktor.

Variabel respon terdiri dari:

$\mathrm{Y}_{1}=$ Persentase Angka Kematian Bayi (AKB)

$\mathrm{Y}_{2}=$ Persentase Status Gizi Buruk (SGB)

SedangkanVariabel Prediktor terdiri dari:

$\mathrm{X}_{1}=$ Persentase Pemberian Asi Eksklusif

$\mathrm{X}_{2}=$ Persentase Bayi Mendapat Imunisasi

$\mathrm{X}_{3}=$ Persentase Kunjungan Ibu Hamil ke Puskesmas untuk memeriksa Kandungan

$\mathrm{X}_{4}=$ Persentase Jumlah Sarana Kesehatan (Puskesmas)

$\mathrm{X}_{5}=$ Persentase Penduduk Miskin

\subsection{Tahapan Analisis}

Tahapan analisis data adalah (1) Mendeskripsikan variabel respon dan prediktor. (2) Menguji korelasi antar variabel respon, apabila tidak terdapat korelasi antar variabel respon maka dilanjutkan dengan analisis regresi univariat. (3) Menguji normal multivariat variabel respon. (4) Menduga parameter model regresi multivariat. (5) Melakukan pemilihan model terbaik dengan memilih satu persatu variabel prediktor dengan kriteria AIC. (6) Menguji signifikansi model regresi multivariat secara serentak dan parsial. (7) Menguji asumsi residual yaitu identik, independent dan berdistribusi normal [11]. 


\section{HASIL DAN PEMBAHASAN}

\subsection{Statistik Deskriptif}

\section{Statistik Deskriptif Variabel Respon}

Statistik deskriptif variabel respon disajikan dalam Tabel 1, berikut:

Tabel 1. Statistik Deskriptif Variabel Respon

\begin{tabular}{|lcccc|}
\hline \multicolumn{1}{|c}{ Variabel Respon } & N & Minimum & Maksimum & Mean \\
\hline Angka Kematian Bayi (AKB) & 11 & 0,00 & 56,00 & 28,6364 \\
\hline Status Gizi Buruk (SGB) & 11 & 0,00 & 0,93 & 0,6318 \\
\hline
\end{tabular}

Berdasarkan Tabel 1, terlihat bahwa nilai $\mathrm{N}=11$ yang menunjukkan jumlah kabupaten/kota yang ada di Provinsi Maluku. Selain itu dapat dilihat juga persentase Angka Kematian Bayi terendah yaitu 0 (tidak terjadi kematian bayi pada tahun itu) di Kabupaten Kepulauan Aru. Sedangkan angka yang tertinggi yaitu sebesar 56 yang terjadi di Kabupaten Maluku Tenggara Barat. Untuk persentase Status Gizi Buruk terendah yaitu sebesar 0 yang terjadi di Kabupaten Seram Bagian Timur, sedangkan angka tertinggi sebesar 0,93 yang terjadi di Kabupaten Kepulauan Aru.

\section{Statistik Deskriptif Variabel Prediktor}

Statistik deskriptif variabel prediktor disajikan dalam Tabel 2, berikut:

Tabel 2. Statistik Deskriptif Variabel Prediktor

\begin{tabular}{|lcccc|}
\hline Variabel Prediktor & N & Minimum & Maksimum & Mean \\
\hline Persentase Pemberian ASI Ekslusif $\left(\mathrm{X}_{1}\right)$ & 11 & 83,55 & 98,87 & 93,7427 \\
\hline Persentase Bayi mendapat Imunisasi $\left(\mathrm{X}_{2}\right)$ & 11 & 11,87 & 73,46 & 37,5045 \\
\hline $\begin{array}{l}\text { Persentase kunjungan ibu hamil ke } \\
\text { Puskesmas }\left(\mathrm{X}_{3}\right)\end{array}$ & 11 & 9,90 & 88,50 & 60,5091 \\
\hline $\begin{array}{l}\text { Persentase Jumlah Sarana } \\
\text { Kesehatan/Puskesmas }\left(\mathrm{X}_{4}\right)\end{array}$ & 11 & 9,00 & 33,00 & 18,0909 \\
\hline Persentasee Penduduk Miskin $\left(\mathrm{X}_{5}\right)$ & 11 & 4,64 & 31,01 & 22,7100 \\
\hline
\end{tabular}

Berdasarkan Tabel 2, telihat bahwa persentase Pemberian ASI Ekslusif terendah yaitu sebesar 83,55\% di Kabupaten Kepulauan Aru sedangkan yang tertinggi sebesar 98,87\% di Kabupaten Buru Selatan. Untuk persentase Bayi mendapat Imunisasi terendah yaitu sebesar 11,87\% di Kabupaten Buru Selatan sedangkan yang tertinggi yaitu sebesar $73,46 \%$ di Kabupaten Maluku Tenggara. Untuk persentase Kunjungan Ibu Hamil ke Puskesmas terendah yaitu sebesar 9,90\% di Kabupaten Kepulauan Aru sedangkan yang tertinggi sebesar 88,50\% di Kabupaten Seram Bagian Timur. Untuk persentase Jumlah Sarana Kesehatan terendah yaitu sebesar 9,00\% di Kabupaten Buru sedangkan yang tertinggi yaitu sebesar 33,00\% di Kabupaten Maluku Tengah. Untuk persentase Penduduk Miskin terendah yaitu sebesar \% di Kota Ambon sedangkan yang tertinggi sebesar 31,01\% di Kabupaten Maluku Barat Daya.

\subsection{Regresi Multivariat}

Sebelum dibentuk suatu model regresi multivariat, terlebih dahulu dilakukan pengujian yaitu pengujian korelasi antar variabel respon dan pengujian normal multivariate variabel respon. Jika variabel respon tidak saling berkorelasi maka analisis dilanjutkan dengan menggunakan regresi univariat, tetapi sebaliknya jika terdapat korelasi antar variabel respon maka akan dilanjutkan analisis dengan menggunakan regresi multivariat [7].

\section{Pengujian Korelasi Antar Variabel Respon}

Untuk menguji korelasi antar variabel respon maka akan digunakan uji Bartlett Sphericity. Hipotesis yang digunakan yaitu [9]:

$\mathrm{H}_{0}$ : Antar variabel respon bersifat independent

$\mathrm{H}_{1}$ : Antar variabel respon bersifat dependent 
Statistik uji yang diperoleh yaitu:

$$
\begin{aligned}
x_{\text {hit }}^{2} & =-\left\{\mathrm{n}-1-\frac{2 q+5}{6}\right\} \ln |\mathrm{R}| \\
& =-\left\{11-1-\frac{2 \times 2+5}{6}\right\} \ln \left|\left[\begin{array}{cc}
1 & -0,726 \\
-0,726 & 1
\end{array}\right]\right| \\
& =-(8,5) \ln (0,473) \\
& =-(8,5)(-0,748)=6,365
\end{aligned}
$$

Dengan menggunakan $\alpha=0,05$ maka diperoleh $x_{0,05 ; 2}^{2}=5,991$. Karena nilai $x_{\text {hit }}^{2}=6,365$ lebih besar dari nilai $x_{0,05 ; 2}^{2}=5,991$ maka Tolak $\mathrm{H}_{0}$ sehingga antar variabel respon bersifat dependent atau antar variabel respon saling berkorelasi.

\section{Distribusi Normal Multivariat Variabel Respon}

Asumsi selanjutnya yang harus dipenuhi dalam analisis regresi multivariat adalah variabel respon berdistribusi normal multivariat. Analisis yang digunakan adalah dengan menggunakan nilai square distance $\left(d_{i}^{2}\right)$. Hipotesis yang digunakan yaitu:

$\mathrm{H}_{0}$ : Variabel respon berdistribusi normal multivariat

$\mathrm{H}_{1}$ : Variabel respon tidak berdistribusi normal multivariat

Hasil yang diperoleh adalah sebagai berikut:

Tabel 3. Distribusi Normal Multivariat

\begin{tabular}{|c|c|c|c|}
\hline Kabupaten/ Kota & $d_{i}^{2}$ & Kabupaten/ Kota & $d_{i}^{2}$ \\
\hline Maluku Tenggara Barat & 2,73224 & Seram Bagian Timur & 1,70413 \\
\hline Maluku Tenggara & 5,48220 & Maluku Barat Daya & 1,97191 \\
\hline Maluku Tengah & 6,59034 & Buru Selatan & 6,71591 \\
\hline Buru & 3,75725 & Kota Ambon & 7,87845 \\
\hline Kepulauan Aru & 7,81502 & Kota Tual & 1,85552 \\
\hline Seram Bagian Barat & 3,49702 & & \\
\hline
\end{tabular}

Berdasarkan Tabel 3, terlihat bahwa dari 11 kabupaten/kota, terdapat 7 kabupaten/kota atau sebesar 64\% menunjukan nilai $d_{i}^{2}<x_{\text {tabel }}^{2}=5,991$. Karena sudah lebih dari 50\% maka terima $\mathrm{H}_{0}$ sehingga variabel respon berdistribusi normal multivariat. Karena pengujian korelasi antar variabel respon dan pengujian normal multivariate variabel respon telah terpenuhi maka dapat dilanjutkan analisis regresi multivariat.

\subsection{Estimasi Parameter}

Selanjutnya dilakukan estimasi parameter model dengan melibatkan semua variabel prediktor. Hasil yang diperoleh adalah sebagai berikut:

Tabel 4. Hasil Estimasi Parameter

\begin{tabular}{|lcr|}
\hline Variabel Respon & Parameter & Nilai Duga \\
\hline \multirow{4}{*}{ Angka Kematian Bayi } & $\beta_{0}$ & $-519,4103$ \\
& $\beta_{1}$ & 2,8730 \\
& $\beta_{2}$ & $-0,2187$ \\
& $\beta_{3}$ & 4,3503 \\
& $\beta_{4}$ & 1,7501 \\
& $\beta_{5}$ & 0,2593 \\
\hline \multirow{4}{*}{ Status Gizi Buruk } & $\beta_{0}$ & 5,5322 \\
& $\beta_{1}$ & $-0,0215$ \\
& $\beta_{2}$ & 0,0024 \\
& $\beta_{3}$ & $-0,0438$ \\
& $\beta_{4}$ & $-0,0088$ \\
& $\beta_{5}$ & $-0,0133$ \\
\hline
\end{tabular}




\subsection{Pemilihan Model Terbaik Dengan Metode AIC}

Langkah awal untuk pemilihan model dengan menggunakan kriteria AIC adalah membentuk model dengan memasukan satu persatu variabel prediktor [10]. Dari pemodelan regresi multivariat dengan menggunakann kriteria AIC diperoleh model terbaik untuk AKB $\left(\mathrm{Y}_{1}\right)$ dan SGB $\left(\mathrm{Y}_{2}\right)$ dengan nilai AIC sebesar 8,440420 dan 0,6999986. Model tersebut dengan nilai AIC terkecil yaitu:

$$
\begin{aligned}
& Y_{1}=-614,55+1,14 X_{1}+2,68 X_{3}+0,09 X_{4}+0,25 X_{5} \\
& Y_{2}=0,16-0,02 X_{1}-0,01 X_{3}-0,005 X_{4}-0,028 X_{5}
\end{aligned}
$$

\subsection{Pengujian Signifikansi Model}

Selanjutnya dilakukan pengujian signifikansi secara serentak maupun parsial

\section{Pengujian Signifikansi Model Secara Serentak}

Pengujian secara serentak dilakukan dengan tujuan untuk mengetahui signifikansi parameter secara keseluruhan dalam model dengan menggunakan uji Wilk's Lambda. Hipotesis yang digunakan yaitu [12]:

$$
\begin{aligned}
& \mathrm{H}_{0}: \hat{\beta}_{11}=\hat{\beta}_{12}=\cdots=\hat{\beta}_{p 1}=\cdots \hat{\beta}_{p q}=0 \text { (model tidak signifikan) } \\
& \mathrm{H}_{1}: \text { paling sedikit ada satu } \hat{\beta}_{p q} \neq 0 \text { (model signifikan) }
\end{aligned}
$$

Berdasarkan hasil analisis diperoleh nilai signifikansi Wilk's Lambda sebesar 0,021. Karena nilai signifikansi kurang dari nilai $\alpha(0,05)$ maka tolak $\mathrm{H}_{0}$ sehingga dapat dikatakan bahwa paling sedikit ada satu parameter yang berpengaruh terhadap angka kematian bayi dan status gizi buruk.

\section{Pengujian Sigfikansi Model Secara Parsial}

Untuk pengujian signifikansi model secara parsial digunakan uji multivariat Wilk's Lambda. Hasil yang diperoleh disajikan dalam Tabel 5, sebagai berikut:

Tabel 5. Hasil Uji Wilk's Lambda

\begin{tabular}{|c|c|}
\hline Parameter & Sig. \\
\hline$\beta_{1}$ & 0,002 \\
$\beta_{3}$ & 0,007 \\
$\beta_{4}$ & 0,007 \\
$\beta_{5}$ & 0,002 \\
\hline
\end{tabular}

Berdasarkan Tabel 5, terlihat bahwa nilai signifikan dari ke-4 variabel kurang dari 0,05 sehingga ke-4 variabel prediktor signifikan mempengaruhi variabel respon. Maka faktor-faktor yang berpengaruh terhadap angka kematian bayi $\left(\mathrm{Y}_{1}\right)$, dan status gizi buruk $\left(\mathrm{Y}_{2}\right)$ di Provinsi Maluku yaitu persentase Pemberian ASI Ekslusif $\left(\mathrm{X}_{1}\right)$, persentase kunjungan ibu hamil ke Puskesmas untuk memeriksa kandungan $\left(\mathrm{X}_{3}\right)$, persentase jumlah sarana kesehatan/puskesmas $\left(\mathrm{X}_{4}\right)$ dan persentase penduduk miskin $\left(\mathrm{X}_{5}\right)$.

\subsection{Uji Asumsi Residual IIDN}

\section{Uji Asumsi Residual Identik}

Asumsi selanjutnya yang harus dipenuhi dalam pemodelan secara multivariat adalah matriks variankovarian residual homogen. Pengujian dilakukan terhadap nilai dari residual yang terlihat. Hipotesis yang digunakan yaitu [5]:

$$
\begin{aligned}
& \mathrm{H}_{0}: \Sigma_{1}=\Sigma_{2}=\Sigma \\
& \mathrm{H}_{1}: \text { Minimal ada satu } \Sigma_{i} \neq \Sigma_{j} \text { untuk } i \neq j
\end{aligned}
$$

Berdasarkan hasil analisis diperoleh nilai statistic uji Box's-M adalah 3,529 dan nilai $p$-value sebesar 0,446. Karena nilai $p$-value lebih dari nilai $\alpha(0,05)$ maka terima $\mathrm{H}_{0}$ yang artinya matriks varian-kovarian residual homogen sehingga dapat disimpulkan bahwa residual identik. 


\section{Uji Residual Saling Bebas (Independent)}

Selain asumsi matriks varian-kovarian residual homogen, asumsi residual saling bebas juga harus dipenuhi [6]. Pengujian asumsi ini dilakukan dengan uji Bartlett Sphercity. Hipotesis yang digunakan yaitu:

$$
\begin{aligned}
& \mathrm{H}_{0} \text { : Residual bersifat independent } \\
& \mathrm{H}_{1} \text { : Residual bersifat dependent }
\end{aligned}
$$

Berdasarkan hasil analisis diperoleh nilai $x_{\text {hit }}^{2}=1,792$. Dengan menggunakan $\alpha=0,05$ maka diperoleh $x_{0,05 ; 2}^{2}=5,991$. Karena $x_{\text {hit }}^{2}=1,792$ lebih kecil dari nilai $x_{0,05 ; 2}^{2}=5,991$ maka terima $\mathrm{H}_{0}$ sehingga dapat dikatakan bahwa residual bersifat independent (saling bebas).

\section{Uji Asumsi Residual Berdistribusi Normal}

Selanjutnya asumsi yang harus dipenuhi adalah residual berdistribusi normal multivariat. Hipotesis yang digunakan yaitu :

$\mathrm{H}_{0}$ : Residual berdistribusi normal multivariat

$\mathrm{H}_{1}$ : Residual berdistribusi tidak normal multivariat

Hasil yang diperoleh adalah sebagai berikut:

Tabel 6. Distribusi Normal Multivariat untuk Residual

\begin{tabular}{|l|l|}
\hline \multicolumn{2}{|c|}{$d_{i}^{2}$} \\
\hline 4,30177 & 5,00055 \\
\hline 0,17170 & 0,65205 \\
\hline 2,32594 & 0,92778 \\
\hline 1,46945 & 0,71162 \\
\hline 0,45590 & 0,36916 \\
\hline 3,61407 & \\
\hline
\end{tabular}

Berdasarkan Tabel 6, terlihat bahwa 11 pengamatan (100\%) menunjukan nilai $d_{i}^{2}<x_{\text {tabel }}^{2}=5,991$. Karena sudah lebih dari $50 \%$ maka terima $\mathrm{H}_{0}$ sehingga residual berdistribusi normal multivariat.

\section{KESIMPULAN}

Berdasarkan hasil analisis data dan pembahasan maka dapat dibuat kesimpulan, sebagai berikut:

1. Berdasarkan pemilihan model dengan menggunakan kriteria AIC, maka,didapatkan model terbaik yaitu: $\mathrm{Y}_{1}=-614,55+1,14 \mathrm{X}_{1}+2,68 \mathrm{X}_{3}+0,09 \mathrm{X}_{4}+0,25 \mathrm{X}_{5}$ dengan nilai AIC sebesar 8,440420

$\mathrm{Y}_{2}=0,16-0,02 \mathrm{X}_{1}-0,01 \mathrm{X}_{3}-0,005 \mathrm{X}_{4}-0,028 \mathrm{X}_{5}$ dengan nilai AIC sebesar 0,6999986

2. Faktor-faktor yang mempengaruhi angka kematian bayi dan status gizi buruk di Provinsi Maluku dengan menggunakan regresi linier multivariat adalah persentase Asi Ekslusif $\left(\mathrm{X}_{1}\right)$, persentase kunjungan ibu hamil ke puskesmas untuk memeriksa kandungan $\left(X_{3}\right)$, persentase jumlah sarana kesehatan/Puskesmas $\left(\mathrm{X}_{4}\right)$ dan persentase penduduk miskin $\left(\mathrm{X}_{5}\right)$

\section{DAFTAR PUSTAKA}

[1] Apriadji, Wied Hary, Gizi Keluarga, Jakarta: Penebar Swadaya, 1986.

[2] Badan Pusat Statistik Maluku, “ Analisa Penyusunan Kinerja Makro Ekonomi dan Sosial Maluku Tahun 2015,” Badan Pusat Statistik Provinsi Maluku, 2015.

[3] Badan Pusat Statistik Maluku, "Badan Pusat Statistik Provinsi Maluku," dalam Laporan Eksekutif Kesehatan Provinsi Maluku, 2015.

[4] Deparet emen Kesehatan RI, “Indikator Sehat Indonesia 2010 dan Pedoman Penetapan Indikator Provinsi Sehat dan Kabupaten/Kota Sehat, Keputusan Menteri Kesehatan No. 1202/Menkes/SK/VIII/2003,” Departemen Kesehatan RI, , Jakarta, 2003.

[5] Draper, N, \& Smith, H, Analisis Regresi Terapan, Jakarta: Gramedia, 1992. 
[6] Gujarati, Damodar, Dasar- Dasar Ekonometrika, Jakarta: Erlangga, 2006.

[7] Johnson, R.A, \& Wichern, D, Applied Multivariat Statistical Analysis, New Jersey: Prentice Hall, 2007.

[8] Melvie Matulessy, SE. MA, "Kematian Bayi di Maluku masih Tinggi," www.tribun-maluku.com, 2017.

[9] Morrison, D.F, "Multivariat Statistical Methods, Fourth Edition,", The Wharton Scool University of Pennsylvania, 2005.

[10] Priyatno, Duwi, Analisis KORELASI, REGRESI dan MULTIVARIAT dengan SPSS, Yogyakarta: iv+126 hlm: Gava Media, 2013.

[11] Rencher, A.R, Methods of Multivariat Analysis Second Edition, New York.: John Wiley \& Sons, 2002.

[12] Sawyer, S. (2010), “Multivariate Linier Models,” http://www.math. wustl.edu/, Diakses pada tanggal Juni 2014. 
